\title{
Physiological and Transcriptomic Responses of Antioxidant System and Nitrogen Metabolism in Tomato Roots Treated With Nitrogen Starvation and Re-Supply
}

\section{Yanyan Dong}

Kunming University of Science and Technology

\section{Manqi Wang}

Kunming University of Science and Technology

\section{Fanzhang Wu}

Kunming University of Science and Technology

Jinping Yan

Kunming University of Science and Technology

Kunzhi Li

Kunming University of Science and Technology

Huini Xu ( $\nabla$ xuhn@kust.edu.cn )

Kunming University of Science and Technology

\section{Research Article}

Keywords: Antioxidant enzyme, tomato, transcriptome, $\mathrm{N}$ metabolism

Posted Date: February 18th, 2021

DOI: https://doi.org/10.21203/rs.3.rs-202253/v1

License: (c) (i) This work is licensed under a Creative Commons Attribution 4.0 International License.

Read Full License 


\section{Abstract}

Nitrogen $(\mathrm{N})$ is one of the essential macronutrients that plays important roles in plant growth and development. To better understand the response of antioxidant system and $\mathrm{N}$ metabolism under $\mathrm{N}$ starvation and re-supply condition, physiological and transcriptomic analysis were performed in tomato roots. The malondialdehyde (MDA) and reactive oxygen species (ROS) contents increased significantly in tomato seedlings after $\mathrm{N}$ starvation for $24 \mathrm{~h}$. The activities of superoxide dismutase (SOD), catalase (CAT), ascorbate peroxidase (APX) and monodehydroascorbate reductase (MDHAR), the ratio of ASA/DHA and GSH/GSSG, the $\mathrm{NO}_{3}{ }^{-}$contents, nitrate reductase (NR) activity were decreased after $\mathrm{N}$ starvation treatment and increased after $\mathrm{N}$ re-supply for $24 \mathrm{~h}$. Compared with the control, 1766 genes were up-regulated and 2244 genes were down-regulated after $\mathrm{N}$ starvation in tomato. These differentially expressed genes (DEGs) are mainly enriched in functional items such as cellular process, metabolic process and catalytic activity. The KEGG pathways revealed that the DEGs were mainly involved in phenpropane biosynthesis, amino sugar and nucleotide sugar metabolism, and $\mathrm{N}$ metabolism. The expression patterns of tomato SISOD, SICAT, SIAPX, SIMDHAR, thioredoxin (SITrxh), peroxiredoxin (SIPrX) and glutaredoxin (SIGrx) genes, and nitrate transporter SINRT2.4, SINR, glutamine synthetase (SIGS2), nitrite reductase ( $\mathrm{SINiR}$ ) decreased after $\mathrm{N}$ starvation and increased after $\mathrm{N}$ re-supply, which were validated by qRT-PCR. Our results provide a basis for understanding the response of tomato to $\mathrm{N}$ deficiency and re-supply and a theoretical reference for cultivation regulation.

\section{Introduction}

Nitrogen $(\mathrm{N})$ is an extremely important and necessary macronutrient for plant growth, which is also the main component of nucleic acids, proteins, enzymes, and chlorophyll. $\mathrm{N}$ has an important role in plant physiological metabolism and growth, and its supply will directly affect plant growth and the accumulation of secondary metabolites (Liu et al. 2017). $\mathrm{N}$ containing fertilizers are applied to all important agronomic and horticultural crops to fulfill their requirement, however, only $30-40 \%$ of that fertilizers are utilized by the crops, while the rest of $\mathrm{N}$ is lost through leaching or volatilization and causes environmental pollution along with loss of resources (Curci et al. 2017; Xin et al. 2019). The unused compounds released into the environment cause environmental pollution, such as soil acidification, soil hardening, and eutrophication of water (Gutiérrez 2012). Thus, improving the nitrogen use efficiency (NUE) is an important object in the world's agricultural modernization and development. A better knowledge of mechanisms regulating nitrate response in plants will help to develop a strategy to enhance NUE, leading to decrease the use of $\mathrm{N}$ fertilizers(Yang et al. 2017).

Organic and inorganic $\mathrm{N}$ can be used by plants (Nasholm et al. 2009; Gruffman et al. 2014), inorganic $N$ resources such as nitrate $\left(\mathrm{NO}_{3}{ }^{-}\right)$and ammonium $\left(\mathrm{NH}_{4}{ }^{+}\right)$are the major $\mathrm{N}$ forms in soil, the former being more abundant in aerobic soils, the latter the major $\mathrm{N}$ compound in flooded wetland or acidic soils (Xu et al. 2012; Curci et al. 2017). Nitrogen metabolism is the most important physiological activity in plants, which is closely related to the growth and development, yield and quality of plants (Zhi et al. 2010). 
Nitrate as a nutrient, is absorbed by roots through low and high affinity nitrate transporters (NRT1 and NRT2), which is reduced to nitrite by nitrate reductase (NR), and to ammonium by nitrite reductase (NiR). Ammonium is then incorporated into amino acids by glutamine synthetase (GS) and glutamate synthase (GOGAT) (Bolton and Thomma 2008; Rajendran et al. 2008; Pagaling et al. 2014; Chen et al. 2018). As a signal, nitrate induces the expression of a number of genes including NRT1, NRT2, NR, NiR (Bolton and Thomma 2008; Rajendran et al. 2008), GS and GOGAT (Li et al. 2012; Rajendran et al. 2008; Pagaling et al. 2014).

The response of nitrogen metabolism in plants to the change of nitrogen level is multifaceted, and the current research on nitrogen metabolism in plants is mostly concentrated in corn, cereals, wheat and other crops. For example, the activity of nitrate reductase in corn increased with the increase of nitrogen level, which indicated that proper nitrogen application could significantly improve the nitrogen use efficiency (Zhan and Lynch 2015). Studies have shown that the lack of nitrogen in the soil of cereal crops will lead to the change of root length and reduce the protein content of grains (York et al. 2015). In addition, extensive transcriptomic studies have investigated nitrogen metabolisms in plants at various levels, such as time points after $\mathrm{N}$ treatments (Krouk et al. 2010), $\mathrm{N}$ sources (Patterson et al. 2010), and rates (Wang et al. 2007), in cell (Picault et al. 2002), and tissue types (Wang et al. 2003). In pear roots resupplied by nitrate starvation, the KEGG pathways revealed that 15 unigenes were related to nitrogen metabolism and significantly differentially expressed in response to nitrate starvation and a nitrate resupply treatment (Chen et al. 2018).

Under the stress of nitrogen deficiency, the dynamic balance between the production and removal of reactive oxygen species (ROS) in plants is broken, which leads to excessive production of ROS in plant cells. If it is not removed in time, it will cause peroxidation of the plasma membrane, thus disrupting the normal metabolism of cells and destroying the integrity of the membrane (Del Río 2015). The types of ROS include superoxide anion $\left(\mathrm{O}_{2}^{-}\right)$, hydrogen peroxide $\left(\mathrm{H}_{2} \mathrm{O}_{2}\right)$, hydroxyl radical $(\cdot \mathrm{OH})$, alkoxy radical (RO•), peroxy radical (ROO•) and singlet oxygen $\left({ }^{1} \mathrm{O}_{2}\right)$ (Parisa 2012). In order to ensure their normal metabolic function, plants will form an antioxidant system which can adapt and resist ROS. Antioxidant system is divided into enzymatic antioxidant system and non-enzymatic antioxidant system. Antioxidant enzyme system mainly includes superoxide dismutase (SOD), peroxidase (POD), activity catalase (CAT) ascorbate peroxidase (APX) and other enzymes, non-enzymatic antioxidant systems include AsA, GSH, carotenoids and so on. There are many reports about the antioxidant system of plants under abiotic stress. For example, accumulation of ROS under drought is a prototypic case of stress-induced responses. There are related reports in corn (Avramova et al. 2015), rice (Cai et al. 2015) and Ailanthus altissima (Laxa et al. 2019), mulberry (Morus alba L.) seedling leaves under $\mathrm{NaCl}$ and $\mathrm{NaHCO}_{3}$ stress. Under $\mathrm{NaCl}$ stress, the activity of SOD, POD and CAT in leaves increased by some extent. Under $\mathrm{NaHCO}_{3}$ stress, the activity of SOD and POD significantly increased, while that of CAT decreased compared to that of control. The ascorbic acid-glutathione (AsA-GSH) cycle in mulberry seedling leaves was enhancement in both $\mathrm{NaCl}$ and $\mathrm{NaHCO}_{3}$ stress (Huihui et al. 2020). Research on rice found that nitrogen stress induces changes in plant ROS content and antioxidant enzyme activity, helping plants resist the damage caused 
by oxidative stress (Kumagai et al. 2009). However, there is no report on the effect of nitrogen deficiency and nitrogen re-supply on the antioxidant system of tomato roots.

RNA-Seq, one of next-generation high-throughput sequencing technologies, has been widely used recently, due to low background noise, high sensitivity and reproducibility, great dynamic range of expression and base pair resolution for transcription profiling (Marioni et al. 2008; Quan et al. 2016). Using this technique, transcriptomic profiles of many plants have been dissected under any given conditions, including biotic and abiotic stresses(Nawaz et al. 2018), such as heat stress (Harada and Burton 2020) and drought stress (Hubner et al. 2015). Whole transcriptome analyses using RNA-Seq to examine genes involved in $\mathrm{N}$ deficiency have been done for Arabidopsis(Shin et al. 2018), maize (Humbert et al. 2013), sorghum (Li et al. 2012; Gelli et al. 2017), cucumber(Xin et al. 2017; Zhao et al. 2015), rice (Yang et al. 2015a; Yang et al. 2015b) ,wheat (Curci et al. 2017; Wang et al. 2019), and watermelon (Nawaz et al. 2018).

Tomato is cultivated on a commercial scale across the world. According to National Bureau of Statistics of China, annual use of nitrogenous fertilizer exceeds 24 million tons (Xin et al. 2017), a fair share of this nitrogenous fertilizer is utilized for tomato production. However, little research is available on tomato seedlings in response to $\mathrm{N}$ deficiency and $\mathrm{N}$ re-supply. In this study, an RNA-sequencing approach was applied to gain a comprehensive picture of transcriptional mechanisms underlying the response to $\mathrm{N}$ deprivation and $\mathrm{N}$ re-supply of tomato roots. In addition, to better characterize the overall effects of these treatments on plant physiological status, the antioxidant enzyme system and $\mathrm{N}$ metabolism were also assessed in the experiment. Our results provide a basis for understanding the molecular mechanisms of tomato's response to $\mathrm{N}$ recovery after $\mathrm{N}$ deficiency stress and laid a theoretical foundation for cultivation.

\section{Material And Methods}

\section{Plant Material and Growth Conditions}

Tomato seeds were soaked in warm water at $55^{\circ} \mathrm{C}$ for $1 \sim 2 \mathrm{~h}$, then placed in a petri dish covered with two layers of wet filter paper and put in a thermostat at $28^{\circ} \mathrm{C}$ for germination. After 2 days, seeds with similar bud potential are sown in perlite with nutrient solution. When tomato seedling grows to a true leaf, they are moved to $4 \mathrm{~L}$ square basins for Hoagland's nutrient solution with twelve seedlings each basin (Siddiqi et al. 2002). At three-leaves stage, seedlings were exposed to nitrogen-free nutrients solution ( $\mathrm{N}$ starvation) for 2 days, after which the tomato seedlings were transferred into Hoagland's nutrient solution with $2.5 \mathrm{mM} \mathrm{Ca}\left(\mathrm{NO}_{3}\right)_{2}$ and $5 \mathrm{mM} \mathrm{KNO}_{3}$ which contained $10 \mathrm{mM} \mathrm{NO}_{3}{ }^{-}$as normal nitrogen. There are 4 treatments in this experiment: (1) normal treatment (CK), tomato nutrient solution cultivation; (2) N deficiency for 2 days, reduction of $\mathrm{N}$ elements on the basis of tomato nutrient solution (CK-N); (3) After 2 days of $\mathrm{N}$ deficiency, use normal tomato nutrition culture for $6 \mathrm{~h}$ (T1); (4) After 2 days of $\mathrm{N}$ deficiency, use normal tomato nutrition culture for $24 \mathrm{~h}$ (T2). Three replicates were set for each treatment, with 36 tomato seedlings in each treatment. Samples were taken after the treatment, and the young roots of tomato were quickly placed in liquid $\mathrm{N}$ for freezing, and then stored in a refrigerator at $-80^{\circ} \mathrm{C}$. 


\section{The lipid peroxidation and ROS accumulation analysis}

The lipid peroxidation level was investigated with the malondialdehyde (MDA) contents determined by Draper and Hadley (1990). The ROS accumulation was assayed used the 2, 7-dichlorofluorescein diacetate $\left(\mathrm{H}_{2}\right.$ DCF-DA) fluorescence probe. The root tips of the treated seedlings were washed with purified water, and then put into EP tube containing $20 \mu \mathrm{mol} \cdot \mathrm{L}^{-1} \mathrm{H}_{2}$ DCF-DA dye for $30 \mathrm{~min}$, washed with $20 \mathrm{mmol} \cdot \mathrm{L}^{-1} \mathrm{HEPES}-\mathrm{KOH}$ (PH:7.8) buffer solution for 3 times, each time for $15 \mathrm{~min}$, and the washed root tip samples were photographed under microscope.

\section{Antioxidant enzyme activities analysis}

$0.2 \mathrm{~g}$ of tomato seedling roots were grinded in ice bath in precooled mortar. $1 \mathrm{~mL}$ of enzyme extract (50 $\mathrm{mmol} \cdot \mathrm{L}^{-1}, \mathrm{PH}: 7.8$, phosphate buffer, $1 \mathrm{mmol} \cdot \mathrm{L}^{-1}$ EDTA, $1 \mathrm{mmol} \cdot \mathrm{L}^{-1}$ ASA and $\left.1 \% \mathrm{PVP}\right)$ was add after grinding into $2 \mathrm{~mL}$ centrifuge tube, then centrifuged at $4^{\circ} \mathrm{C}$ and $12000 \mathrm{rpm}$ for $20 \mathrm{~min}$. The supernatant was used to measure enzyme activity, and the experiment was set up in 3 repetitions. The activity of SOD was determined by measuring its ability to inhibit the photochemical reduction of nitroblue tetrazolium (NBT) spectrophotometrically at $560 \mathrm{~nm}$ (Madhava Rao and Sresty 2000). CAT activity was determined as described by Madhava Rao and Sresty (2000). The activities of APX were determined according to the methods of Yoshiyuki et al. (1981). The activity of monodehydroascorbate reductase (MDHAR) was determined according to Krivosheeva et al. (1996).

\section{Antioxidant substances contents analysis}

$0.2 \mathrm{~g}$ tomato seedling roots were added with $1 \mathrm{~mL}$ precooled $5 \%$ sulfosalicylic acid, grounded in ice bath, centrifuged at $12000 \mathrm{rpm}$ for $20 \mathrm{~min}$ at $4^{\circ} \mathrm{C}$, and the supernatant was taken for later use. The contents of reduced ascorbic acid (AsA) and oxidized dehydroascorbic acid (DHA) were determined by Bipyridine method (Jiang et al. 2001). Oxidized glutathione (GSSG) and reduced glutathione (GSH) were determined by Nagalakshmi and Prasad' DTNB method (Nagalakshmi and Prasad 2001).

\section{Determination of nitrate contents and nitrate reductase activities}

The nitrate ion concentration was determined according to Cataldo's methods (CATALDO and Analysis 1975). The activity of nitrate reductase was measured by Living body method (Hageman and Reed 1971). Tomato roots after different nitrogen treatments were rinsed with distilled water and dried with absorbent paper, cut into small pieces with scissors, weighed $0.5 \mathrm{~g}$ with a small balance, and put into a triangular flask. First add $1 \mathrm{~mL}$ of $30 \%$ trichloroacetic acid solution to the control triangular flask, then add $4 \mathrm{~mL}$ of $0.1 \mathrm{~mol} \mathrm{~L}^{-1}$ phosphate buffer ( $\left.\mathrm{pH}: 7.5\right)$ and $5 \mathrm{~mL} 0.2 \mathrm{~mol} \mathrm{~L}^{-1} \mathrm{KNO}_{3}$ to each triangular flask after mixing, put it in a desiccator immediately and evacuate it for 30 minutes. During this period, let in air several times, and then evacuate to make the blade sink completely into the bottom of the bottle, and then put it at $25^{\circ} \mathrm{C}$ for 30 minutes, add $1 \mathrm{~mL}$ of $30 \%$ trichloroacetic acid solution to the triangular flask to stop the reaction. After shaking each triangular flask and let stand for two minutes, then, $2 \mathrm{~mL}$ of the 
supernatant was treated with $4 \mathrm{~mL} 1 \%$ sulfonamide and $0.2 \%$ a-naphthylamine before incubating for 15 min in a $35^{\circ} \mathrm{C}$ water bath with agitation. The nitrate content and nitrate reductase activity were then measured at $410 \mathrm{~nm}$ and $540 \mathrm{~nm}$, respectively, using a spectrophotometer.

\section{RNA extraction and detection}

RNA was extracted using TransZolUp (TRANS, Company) with approximately $0.1 \mathrm{~g}$ sample according to the TRNAS kit instructions. After the RNA extraction is completed, RNA is subjected to $1.0 \%$ gel electrophoresis to ensure the purity and integrity.

\section{Transcriptome sequencing sample preparation and library establishment}

After extracting total RNA from the sample, enrich the mRNA with magnetic beads with Oligo (dT), adding fragmentation buffer to the obtained mRNA to make fragments therefore into short fragments, then the mRNA after the fragment is taken as a template. The first strand of cDNA was synthesized with random hexamers. Add buffer, dNTPs, RNase $\mathrm{H}$ and DNA polymerase I to synthesize cDNA second chain. The cDNA was purified by QiaQuick PCR test kit and eluted with EB buffer solution, and subjected to end repair. Add base $A$, add sequencing linker, and then recover the target size fragment by agarose gel electrophoresis, and carry out PCR amplification to complete the whole library preparation work. The constructed library was sequenced by Illumina HiSeq TM. Guangzhou Gidiao Technology company Ltd. was commissioned to complete the library construction, Illumina HiSeq TM sequencing and gene function annotation.

\section{Transcriptome data assembly}

First, we filter the Raw data, remove low quality and connectors to obtain Clean data, and use TopHat to compare and remove rRNA-containing reads respectively. Then,the reads of the filtered rRNA are compared to a reference genome. Finally, transcript reconstruction is carried out by cufflinks to obtain all transcripts.

\section{Differential expression gene (DEG) analysis and gene function annotation}

The original data is standardized by using the DESeq's own standardized method. In the process of difference analysis, the negative binomial distribution method is used to estimate the distribution of Read count, after evaluating and calculating $P$ value, multiple hypothesis tests are performed on $P$ value to reduce false positives. Differentiated genes were screened according to edgeR's general filtering criteria $\left(\log _{2} \mid\right.$ Fold Change| $>1$ \& FDR $\left.<0.05\right)$, and the screened differentially expressed genes were enriched with gene ontology (GO) and Kyoto Encyclopedia of Genes and Genomes (KEGG) to determine the major metabolic pathways.

\section{Quantitative real-time PCR (qRT-PCR) analysis}


Total RNA was extracted and cDNA was synthesized by Prime Script TM RT regent kit with gDNA Eraser (Perfect Real Time), and fluorescence quantitative assay was carried out by abm® Eva Green qPCR Master Mix-no dye kit. The primers were designed with Software Premier 5.0 based on cDNA Fragments (Table S1). The Pre-denaturation of reaction program was $95^{\circ} \mathrm{C}, 5 \mathrm{~min}$. The number of reaction cycles is 40 , the cycle process is $95^{\circ} \mathrm{C}, 10 \mathrm{~s}, 60^{\circ} \mathrm{C}, 30 \mathrm{~s} ; 72^{\circ} \mathrm{C}, 20 \mathrm{~s}$. The specificity was evaluated by dissolution curve and size estimation of amplification products. The expression level of DEGs was calculated with

$2^{-\Delta \Delta c t}$. Actin gene is used as the standardization of the determination gene. Value of each stage is taken as the average of three technical repetitions for each biological repetition.

\section{Statistical analysis}

Three replicates of each sample were used for statistical analysis. Data were analyzed with Student's ttest indicated as follows: ${ }^{*}, P<0.1 ; * \star, P<0.05$. The Graphpad Prism 7.0 software (GraphPad Software, La Jolla California USA, www.graphpad.com) was used for making figures.

\section{Results}

Effects of $\mathrm{N}$ deficiency and re-supply treatments on lipid peroxidation and ROS accumulation in tomato roots

Membrane lipid peroxidation often occurs when plant organs are aged or damaged under adversity. MDA is the final decomposition product of membrane lipid peroxidation, and its content can reflect the degree of damage to plants under adversity. In this experiment, the MDA content of samples was measured at four treatment time points: CK, CK-N, T1 and T2. After two days of N deficiency treatment, the MDA content increased by $89.90 \%$ compared with that of normal tomato seedlings (Fig. 1a). Compared with the control group, MDA content still increased by $38.57 \%$ after re-supplying $\mathrm{N}$ for $6 \mathrm{~h}$, and basically returned to normal level after re-supplying $\mathrm{N}$ for $24 \mathrm{~h}$.

The ROS content in tomato roots was labeled with fluorescent probe $\mathrm{H}_{2}$ DCF-DA (Fig. 1b). The fluorescence degree of ROS in roots treated with $\mathrm{N}$ deficiency was increased dramatically, which indicated that the oxidative damage caused by $\mathrm{N}$ deficiency was aggravated. The fluorescence intensity decreased after re-supplying $\mathrm{N}$, which indicated that the oxidative damage was relieved to some extent after resupplying $\mathrm{N}$.

\section{Effects of $\mathrm{N}$ deficiency and re-supply treatments on antioxidant enzyme activities and ratio of AsAVDHA and GSH/GSSG in tomato roots}

As shown in Fig. 2, the activities of SOD, CAT, APX, and MDHAR in tomato roots were all decreased after N deficiency stress compared with the control. SOD activity decreased by $38.02 \%, 22.01 \%$ and $19.71 \%$ after 2 days of $\mathrm{N}$ deficiency, $\mathrm{N}$ re-supply for $6 \mathrm{~h}$ and $24 \mathrm{~h}$ (Fig. 2a). CAT activity decreased significantly by $48.50 \%$ after $\mathrm{N}$ deficiency stress, and continued to decrease to $59.72 \%$ after $6 \mathrm{~h}$ of $\mathrm{N}$ re-supply (Fig. 2b). APX is an antioxidant enzyme that mainly catalyzes AsA to capture $\mathrm{H}_{2} \mathrm{O}_{2}$ in chloroplasts and cytoplasm 
of plant cells. The APX activity in the roots of tomato seedlings decreased by $32.78 \%$ after $\mathrm{N}$ deficiency, and continued to decrease to $43.45 \%$ after $6 \mathrm{~h}$ of $\mathrm{N}$ re-supply and then increased by $25.02 \%$ after $24 \mathrm{~h}$ of $\mathrm{N}$ re-supply (Fig. 2c). MDHAR is an important enzyme to regenerate AsA in AsA-GSH cycle. MDHAR activities decreased by $60.13 \%$ after $\mathrm{N}$ deficiency and then increased after $\mathrm{N}$ re-supply (Fig. $2 \mathrm{~d}$ ).

The ratio of ASA/DHA and GSH/GSSG in tomato seedling roots decreased after $\mathrm{N}$ deficiency and then increased after $\mathrm{N}$ re-supply (Fig. 2e, f). Compared with the control group, the ratio of GSH/GSSG and ASA/DHA decreased by $29.15 \%$ and $36.22 \%$, respectively, after 2 days of $\mathrm{N}$ deficiency. The ratio of ASA/DHA increased by $16.15 \%, 21.59 \%$ and the ratio of GSH/GSSG increased by $8.93 \%$, and $17.18 \%$, respectively, after $6 \mathrm{~h}$ and $24 \mathrm{~h}$ of $\mathrm{N}$ re-supply.

\section{Effects of $\mathrm{N}$ deficiency and $\mathrm{N}$ re-supply treatments on $\mathrm{NO}_{3}{ }^{-}$contents, nitrate reductase activity in tomato roots}

After $\mathrm{N}$ deficiency for 2 days, the $\mathrm{NO}_{3}{ }^{-}$content decreased by $39.61 \%$, compared with the control (Fig. 3a). The $\mathrm{NO}_{3}{ }^{-}$content in tomato roots increased by $17.56 \%$ after re-supplying $\mathrm{N}$ for $6 \mathrm{~h}$. The $\mathrm{N}$ re-supply for $24 \mathrm{~h}$ treatments basically restored $\mathrm{NO}_{3}{ }^{-}$accumulation to normal levels.

Nitrate reductase (NR) is a key enzyme in the plant nitrate-assimilation process. Therefore, effects of $\mathrm{N}$ deficiency and the $\mathrm{N}$ re-supplying treatment on the NR activity in tomato roots were investigated. As shown in Fig. 3b, N deficiency treatments significantly reduced the NR activity by $54.78 \%$ in tomato roots. However, the inhibitory effect under conditions of $\mathrm{N}$ deficiency was relieved by the $\mathrm{N}$ re-supply treatment.

\section{Quality analysis of sequencing results}

To investigate the molecular response of $\mathrm{N}$ starvation and re-supply to tomato seedling, RNA-seq technology was used. The sample of tomato roots of the control and the treatment group were sequenced by Illumina HiSeqTM. In order to ensure the quality of the data, the original data should be quality-controlled before information analysis. Removed reads with adapter, reads with $\mathrm{N}$ ratio greater than $10 \%$, and low-quality reads, CK, CK-N, T1, and T2 have 25515430, 22044082, 21551480, and 21513858 clean reads, and the percentage of Q20 (the quality of the bases after filtering is not less than 20 Proportion) reached $98.32 \%, 98.35 \%, 98.27 \%$, and $98.32 \%$, all of which are greater than $90 \%$. The quality is qualified and meets the requirements of subsequent analysis. In this study, tomato samples of treatments CK, CK-N, T1, and T2 treatments had GC contents of $43.46 \%, 43.16 \%, 42.96 \%$, and $42.96 \%$. Removed reads on the ribosome, four processed Unmapped Reads were got, and the total reads are $25233998,20919716,21269156$, and 21301956, respectively. Number of reads on the reference genome for unique alignment and the proportion of the total (Unique Mapped Reads) alignment are 22831684 (90.48\%), 19167292 (91.62\%), 19363835 (91.04\%) and 19472134 (91.41\%). The above data will be used for assembly and analysis of the transcriptome (Table 1).

PCA results showed that there was a significant difference in gene expression between the CK group and the CK-N group. The gene expression of the T1 group showed a recovery phenomenon, and the gene 
expression of the CK group samples was similar to that of the T2 group samples (Fig. S1). The results showed that the gene expression level basically recovered to that of the CK group of the hydroponic tomato roots resumed $\mathrm{N}$ culture for $24 \mathrm{~h}$ after 2 days of $\mathrm{N}$ deficiency.

\section{Analysis of differences between samples}

The R-based software package edgeR was used to process the RNA-seq data for pairwise samples or between groups with significant differences. FDR and $\log _{2} \mathrm{FC}$ were used to screen for differential genes, and the screening conditions were FDR $<0.05$ and $\left|\log _{2} \mathrm{FC}\right|>1$. As shown in Fig. 4a, compared the CK with CK-N, there were 4010 significantly different genes, of which 1766 were significantly up-regulated and 2244 were significantly down-regulated. Comparing the CK-N and T1 groups, there were 5441 significantly different genes, of which 3534 were significantly up-regulated and 1907 were significantly down-regulated. Comparing the CK-N and T2 groups, there were 4235 significantly different genes, of which 2233 were significantly up-regulated and 2002 were significantly down-regulated. Compared with the T1 and T2 groups, there were 2817 significantly different genes, of which 839 were significantly upregulated and 1978 were significantly down-regulated.

To identify common and unique DEGs in response to $\mathrm{N}$ starvation and re-supply treatments, venn graphs were plotted. We analyzed DEGs that were transcriptionally regulated at different treatment, and a total of 430 common DEGs were identified among the four libraries (Fig. 4b).

\section{GO function annotation analysis of different expressed genes}

The number of genes with significant differences in $\mathrm{GO}$ function enrichment between each 2 groups is shown in Table S2. These differentially expressed genes are annotated into three directions: biological processes, cell components and molecular functions, involving a total of 45 functional entries. The GO classification charts of Ck-N-vs-T1, Ck-N-vs-T2 and T1-vs-T2 are shown in Fig S2, S3, S4. The GO classification map of CK and CK-N are shown in Fig. 5. In biological processes, differentially expressed genes are most abundant in cellular processes, metabolic processes and single-organism processes. In cell components, differentially expressed genes are mainly concentrated in cell, cell part and membrance. In terms of molecular function, differentially expressed genes are mainly enriched in catalytic activity and binding function items.

\section{Differential gene KEGG Pathway analysis}

In order to further understand the biological function of genes and determine the most important biochemical metabolic pathways and signal transduction pathways involved in DEGs, we performed pathway significant enrichment analysis. 7135 differentially expressed genes were annotated in the KEGG database. In CK and CK-N, CK-N and T1, CK-N and T2, T1 and T2, they were annotated to 124, 126, 125, and 113 pathways, respectively. The top 20 pathways with abundant genes are shown in Fig. 6 and Fig. S5, S6, S7. Among them, the differentially expressed genes are mainly involved in phenylpropanoid 
biosynthesis, amino sugar and nucleotide sugar metabolism, cysteine and methionine metabolism, starch and sucrose metabolism, $\mathrm{N}$ metabolism and other pathways.

\section{Differential expression of $\mathrm{N}$ metabolism genes in tomato}

The metabolic process of $\mathrm{N}$ in plants includes complex mechanisms such as absorption and transport, assimilation and reuse. As shown in Fig. 7, differentially expressed genes were found in this $\mathrm{N}$ metabolism pathway. Compared with the control group, 7 DEGs expressions were down-regulated and 1 DEGs expression was up-regulated in hydroponic tomato roots after $\mathrm{N}$ deficiency. The down-regulated genes were nitrate transporter (Nrt, Solyc06g010250.3), nitrate reductase (NR, Solyc11g013810.2), nitrite reductase (NiR, 1.7.7.1, Solyc01g108630.3), alpha carbonic anhydrase (14.2.1.1, Solyc09g009830.3). Besides, Beta carbonic anhydrase 5 (14.2.1.1, Solyc09g010970.3), Glutamate dehydrogenase (GDH, 1.4.1.3, Solyc05g052100.3), glutamine synthetase (GS, 6.3.1.2, Solyc01g080280.3). Glutamate synthase 1 (GOGAT, 11.4.1.13 and 1.4.1.14 have the same Nr annotation of Solyc03g083440.3) have up-regulation expression.

The genes that are down-regulated or up-regulated due to $\mathrm{N}$ deficiency stress gradually returned to normal expression levels after 1 day of $\mathrm{N}$ restoration.

\section{The expression of antioxidant enzyme genes in qRT-PCR and RNA-seq analysis}

qRT-PCR analysis was performed on the transcription level of SISOD, SICAT, SIAPX and SIMDHAR (Fig. 8). After 2 days of $\mathrm{N}$ deficiency in tomato seedlings, the relative expression of SISOD, SICAT, SIAPX and SIMDHAR genes in tomato roots decreased by $97.37 \%, 94.86 \%, 73.83 \%$ and $83.45 \%$, respectively, compared with the control group. The relative expression of SISOD and SICAT genes increased by 6.55 and 3.76 times respectively after $\mathrm{N}$ re-supply for $6 \mathrm{~h}$. The relative expression of SIAPX and SIMDHAR genes decreased by $74.63 \%$ and $51.24 \%$ respectively after $\mathrm{N}$ re-supply for $6 \mathrm{~h}$. The relative expression of SISOD, SICAT, and SIMDHAR genes increased by 7.54, 8.53 and 1.91 times, and the relative expression of SIAPX genes decreased by $43.89 \%$, after $\mathrm{N}$ re-supply for $24 \mathrm{~h}$.

The mRNA expression of S/Trxh, SIPrx and S/Grx was also analyzed by qRT-PCR in the roots of tomato seedling after the N deficiency and re-supply. SITrxh, SIPrx and SIGrx expression decreased by $56.73 \%$, $93.27 \%$ and $87.31 \%$, respectively, compared with the control group after 2 days of N deficiency. S/Trxh expression decreased by $53.74 \%$ compared with the control group after $6 \mathrm{~h}$ of $\mathrm{N}$ re-supply. SIPrx and S/Grx expression increased by 4.77 and 1.03 times of the control group after $6 \mathrm{~h}$ of $\mathrm{N}$ re-supply. The mRNA expression of SIPrx and SIGrx increased significantly after $24 \mathrm{~h}$ of $\mathrm{N}$ re-supply.

We analyzed the transcriptome, and the results are basically consistent with the real-time PCR data (Table S3), indicating that the transcriptome data is reliable.

\section{The expression of $\mathrm{N}$ metabolism genes in qRT-PCR and RNA-seq analysis}


Compared with the control group, the transcription levels of SINRT2.4, SINR, SINiR and SIGS in hydroponic tomato seedlings were down-regulated by $65.43 \%, 13.22 \%, 73.11 \%$ and $54.72 \%$, respectively, after $\mathrm{N}$ starvation (Fig. 9). Compared with the control group, the transcription level was up-regulated by 1.17, $2.24,2.15$ and 0.59 times after $\mathrm{N}$ re-supplying for $24 \mathrm{~h}$. Compared with the control group, the transcription level of SIGOGAT gene after $\mathrm{N}$ starvation treatment was increased by 2.19 times, and after $24 \mathrm{~h}$ of $\mathrm{N}$ resupplying, the transcription level was only 1.07 times that of the control group, which basically recovered to the level of the control group.

\section{Discussion}

$\mathrm{N}$ is an important and most abundantly required macronutrient for plant growth and development. $\mathrm{N}$ availability directly affects chlorophyll formation and photosynthetic assimilation (Nawaz et al. 2017; Luo et al. 2013; Takei et al. 2001; Tischner 2001; Colla and Science 2010). In our experiment, the ROS contents increased after $\mathrm{N}$ starvation, which indicated that the balance of ROS was disrupted by the $\mathrm{N}$ starvation. MDA content is the embodiment of the degree of cell membrane peroxidation in plants. In this experiment, the content of MDA in the root system of $\mathrm{N}$-deficient tomato was significantly higher than that of the control. The MDA content was also markedly increased in the leaves and roots of wheat seedlings during $\mathrm{N}$ starvation (Guo et al. 2014).

Plants have developed an antioxidant machinery that includes the activity of ROS detoxifying enzymes [e.g., SOD, APX, CAT, and PrX], as well as antioxidant molecules such as ascorbic acid (ASA) and glutathione (GSH) that are present in almost all subcellular compartments (Cassia et al. 2018). Nitrate starvation repress genes related to the cytoskeleton and ROS detoxification (Ravazzolo et al. 2020). In our experiment, compared with the control group, SOD, CAT activities decreased after 2 days of $\mathrm{N}$ deficiency (Fig. 2). The APX in tomato gradually lost its activity after $\mathrm{N}$ deficiency treatment, which may be due to excessive ROS attacking biological functional molecules in defense system under $\mathrm{N}$ deficiency stress (Hasanuzzaman et al. 2019). In the cycle of AsA-GSH in plants, AsA is oxidized to MDHA, and MDHA regenerates AsA under the action of MDHAR. MDHAR activity decreased after $\mathrm{N}$ deficiency, $\mathrm{N}$ re-supply for $6 \mathrm{~h}$ and $24 \mathrm{~h}$, compared with the control group (Fig. 2d). Previous results showed that AsA synthesis in tomato roots was damaged after $\mathrm{N}$ deficiency (Hasanuzzaman et al. 2019). In our study, the ratio of AsA/DHA decreased after $\mathrm{N}$ starvation. Transcripts involved in antioxidant responses were strongly upregulated when $T$. suecica was cultured under $\mathrm{N}$ starvation (Lauritano et al. 2019). However, in our study, the expression of antioxidant enzymes of SISOD, SICAT, SIAPX, SIMDHAR were all decreased after $\mathrm{N}$ starvation in tomato roots, indicating the decreased ROS detoxification capability.

Most of the studies have implicated $N$ transport genes, $N$ assimilation genes, and GS/GOGAT cycle genes involved in NUE. The amount of nitrate ion in tomato root decreased after $\mathrm{N}$ deficiency treatment, which is consistent with the previous studies that the $\mathrm{N}$ starvation condition led to a marked reduction in total $\mathrm{N}$ content in roots (Curci et al. 2017). Under $\mathrm{N}$ limitations, reduced nitrate and total $\mathrm{N}$ concentrations in the $\mathrm{N}$-starved rapeseed plants were also detected (Zhang et al., 2018). In addition, the nitrate ion content basically returned to normal level after supplying $\mathrm{N}$ for $24 \mathrm{~h}$. This indicated that tomato roots in $\mathrm{N}$ 
deficiency state can uptake an adequate supply of nitrate within $24 \mathrm{~h}$ of its being $\mathrm{N}$ resupplied, which are consistent with earlier reports (Chen et al. 2018; Richard-Molard et al. 2008). In previous reports, NR activity decreased under $\mathrm{N}$ deficiency stress in cotton (Iqbal et al. 2020), rice (Sinha et al. 2018), and wheat (Sinha et al. 2015), which was consistent with the results in this paper. In this study, tomato seedlings after two days of N deficiency, GOGAT genes were up-regulated, while the expression of SIGS, $S I N R$, and SINiR genes were down-regulated in tomato roots. Previous research showed that N starvation caused a significant decrease both in transcript levels in NR, NiR, GS, and GOGAT activities. Potassium nitrate treatment restored NR, NiR, GS, and GOGAT expressions and activities (Balotf et al. 2016). These results demonstrate that $\mathrm{N}$ transport and assimilation are adjusted by the GS/GOGAT cycle in response to $\mathrm{N}$ availability. Re-supplying nitrate to the nitrate-starved tomato plants quickly and significantly increases the transcription levels of many genes, such as nitrate transporters, NR, and NiR, in the first $24 \mathrm{~h}$, but this up-regulation trend lasts for $48 \mathrm{~h}$ and then subsides (Scheible et al. 2004).

RNA-seq was a suitable transcriptomic technique to study the molecular mechanism on plant growth and development, plant stress resistance and other aspects under any given condition. Recently, this method has been also performed on some crops, viz rice, sorghum, cucumber and watermelon (Yang et al. 2015a; Zhao et al. 2015; Nawaz et al. 2018; Gelli et al. 2014), to investigate the mechanism of N deficiency tolerance. Re-supplying nitrate to the nitrate-starved Arabidopsis seedlings within $30 \mathrm{~min}$, markedly and extensively alters the expression levels of genes involved in primary and secondary metabolism, cellular growth, hormone responses, protein synthesis, signal transduction and transcriptional regulation (Scheible et al. 2004). lqbal et al. (2020) reported the genotypic difference in transcriptome profile using two cotton genotypes differing in NUE under $\mathrm{N}$ starvation and resupply treatments. A large genetic variation existed in DEGs related to amino acid, carbon, and nitrogen metabolism. The identification of key genes underlying the response to $\mathrm{N}$ starvation may enable novel approaches to increase NUE and to improve plant resilience to nutritional stresses (Ravazzolo et al. 2020). In tomato, 97 genes are differentially expressed when nitrate is resupplied to nitrate-starved tomato plants within 1-96 h (Wang et al. 2001). Functional analysis of the $\mathrm{N}$-starvation response proteins suggested their involvement in protein synthesis and fate, metabolism, and defense of young rice leaves grown under nitrogen-starvation conditions(Kim et al. 2011). N compound metabolism, carbon metabolism, and photosynthesis were mostly enriched in durum wheat under $\mathrm{N}$ starvation (Curci et al. 2017). Metabolic process, cellular process, and transport were enriched in rice roots and shoots under $\mathrm{N}$-free conditions (Yang et al. 2015a). In our study, comparing the two groups of tomato seedling roots treated with $\mathrm{N}$ deficiency and $\mathrm{N}$ resupply, the DEGs were involved in metabolic process, nutrient reservoir activity and catalytic activity responding to $\mathrm{N}$ deficiency and $\mathrm{N}$ re-supply treatment.

KEGG pathway analysis can help us to further understand the biological functions of genes and how these genes interact (Kanehisa et al. 2004). In our study, the differentially expressed genes are mainly involved in the pathways of phenylpropanoid biosynthesis, amino sugar and nucleotide sugar metabolism, cysteine and methionine metabolism, starch and sucrose metabolism, $\mathrm{N}$ metabolism and other pathways. In previous report, cotton under $\mathrm{N}$ starvation and re-supply treatment, enriched to a pathway similar to the results of our experiment (Iqbal et al. 2020). The KEGG pathways revealed that 15 
unigenes, including one NRT gene, two NR genes, one NiR gene, two GDH genes, six GS genes and three GOGAT genes, were related to nitrogen metabolism and significantly differentially expressed in response to nitrate starvation and a nitrate re-supply treatment (Chen et al. 2018). From these pathways explained the possible roles of $\mathrm{N}$ deficiency and re-supply on the $\mathrm{N}$ metabolism of tomato.

In sum, antioxidant enzyme system and $\mathrm{N}$ metabolism were analyzed based on environmental conditions that restored $\mathrm{N}$ supply after two days of $\mathrm{N}$ deficiency in tomato seedlings by physiological and RNA-seq analysis. This study provided a valuable resource for better understanding of tomato seedling roots in responses to $\mathrm{N}$ starvation and re-supply and for understanding the genes and pathways involved.

\section{Declarations}

\section{Author Contributions}

H.N. X designed the project. Y.Y D, M.Q. W, F.Z.W conducted the experiments and analyzed the data. Y.Y D wrote the article. J.P. Y and K.Z. L helped in the writing of the article. All authors agreed on the final content of the article.

\section{Acknowledgments}

This research was funded by the National Natural Science Foundation of China (grant no. 31760582) and the Yunnan Ten Thousand Talents Plan: Young \& Elite Talents Project.

\section{Declaration of Competing Interest}

The authors declare no conflict of interest.

\section{References}

1. Avramova V, Abdelgawad H, Zhang Z, Fotschki B, Casadevall R, Vergauwen L, Knapen D, Taleisnik E, Guisez Y, Asard HJPP (2015) Drought Induces Distinct Growth Response, Protection, and Recovery Mechanisms in the Maize Leaf Growth Zone. 169 (2):1382-1396

2. Balotf S, Kavoosi G, Kholdebarin B (2016) Nitrate reductase, nitrite reductase, glutamine synthetase, and glutamate synthase expression and activity in response to different nitrogen sources in nitrogenstarved wheat seedlings. Biotechnol Appl Bioc 63 (2):220-229

3. Bolton MD, Thomma BPHJ (2008) The complexity of nitrogen metabolism and nitrogen-regulated gene expression in plant pathogenic fungi. Physiol Mol Plant P 72 (4-6):104-110

4. Cai W, Liu W, Wang WS, Fu ZW, Han TT, Lu YTJPO (2015) Overexpression of Rat Neurons Nitric Oxide Synthase in Rice Enhances Drought and Salt Tolerance. 10

5. Cassia R, Nocioni M, Correa-Aragunde N, Lamattina L (2018) Climate Change and the Impact of Greenhouse Gasses: $\mathrm{CO} 2$ and NO, Friends and Foes of Plant Oxidative Stress. Frontiers in plant science 9:273. doi:10.3389/fpls.2018.00273 
6. CATALDO DAJCiSS, Analysis P (1975) Rapid colorimetric determination of nitrate in plant tissue by nitration of salicylic acid. 6

7. Chen G, Li X, Chen Q, Wang L, Qi K, Yin H, Qiao X, Wang P, Zhang S, Wu J, Huang Z (2018) Dynamic transcriptome analysis of root nitrate starvation and re-supply provides insights into nitrogen metabolism in pear (Pyrus bretschneideri). Plant Sci 277:322-333. doi:10.1016/j.plantsci.2018.10.007

8. Colla G, Science CMICSrJHAPotASfH (2010) Improving Nitrogen Use Efficiency in Melon by Grafting. 45 (4):559-565

9. Curci PL, Aiese Cigliano R, Zuluaga DL, Janni M, Sanseverino W, Sonnante G (2017) Transcriptomic response of durum wheat to nitrogen starvation. Sci Rep 7 (1):1176. doi:10.1038/s41598-017-013770

10. Del Río LA (2015) ROS and RNS in plant physiology: an overview. J Exp Bot 66 (10):2827-2837. doi:10.1093/jxb/erv099

11. Draper HH, Hadley MJME (1990) Malondialdehyde determination as index of lipid peroxidation. 186 (186):421

12. Gelli M, Duo Y, Konda AR, Zhang C, Holding D, Dweikat I (2014) Identification of differentially expressed genes between sorghum genotypes with contrasting nitrogen stress tolerance by genomewide transcriptional profiling. BMC Genomics 15:179. doi:10.1186/1471-2164-15-179

13. Gelli M, Konda AR, Liu K, Zhang C, Clemente TE, Holding DR, Dweikat IM (2017) Validation of QTL mapping and transcriptome profiling for identification of candidate genes associated with nitrogen stress tolerance in sorghum. Bmc Plant Biol 17 (1):123. doi:10.1186/s12870-017-1064-9

14. Gruffman L, Jamtgard S, Nasholm T (2014) Plant nitrogen status and co-occurrence of organic and inorganic nitrogen sources influence root uptake by Scots pine seedlings. Tree Physiol 34 (2):205213. doi:10.1093/treephys/tpt121

15. Guo TC, Xuan HM, Yang YY, Wang LN, Wei LT, Wang YH, Kang GZ (2014) Transcription Analysis of Genes Encoding the Wheat Root Transporter NRT1 and NRT2 Families During Nitrogen Starvation. J Plant Growth Regul 33 (4):837-848

16. Gutiérrez RA (2012) Systems Biology for Enhanced Plant Nitrogen Nutrition. 336 (6089):1673-1675. doi:10.1126/science.1217620\%J Science

17. Hageman RH, Reed AJJMiE (1971) [45] Nitrate reductase from higher plants. 69C (69C):270-280

18. Harada AE, Burton RS (2020) Consequences of $<\mathrm{em}>\mathrm{HSF}</$ em $>$ knockdown on gene expression during the heat shock response in <em>Tigriopus californicus</em>. 223 (3):jeb208611. doi:10.1242/jeb.208611 \%J The Journal of Experimental Biology

19. Hasanuzzaman M, Bhuyan M, Anee TI, Parvin K, Nahar K, Mahmud JA, Fujita M (2019) Regulation of Ascorbate-Glutathione Pathway in Mitigating Oxidative Damage in Plants under Abiotic Stress. Antioxidants (Basel) 8 (9). doi:10.3390/antiox8090384

20. Hubner S, Korol AB, Schmid KJ (2015) RNA-Seq analysis identifies genes associated with differential reproductive success under drought-stress in accessions of wild barley Hordeum spontaneum. BMC 
Plant Biol 15:134. doi:10.1186/s12870-015-0528-z

21. Huihui Z, Xin L, Yupeng G, Mabo L, Yue W, Meijun A, Yuehui Z, Guanjun L, Nan X, Guangyu S (2020) Physiological and proteomic responses of reactive oxygen species metabolism and antioxidant machinery in mulberry (Morus alba L.) seedling leaves to $\mathrm{NaCl}$ and $\mathrm{NaHCO} 3$ stress. Ecotoxicology and environmental safety 193:110259. doi:10.1016/j.ecoenv.2020.110259

22. Humbert S, Subedi S, Cohn J, Zeng B, Bi YM, Chen X, Zhu T, McNicholas PD, Rothstein SJ (2013) Genome-wide expression profiling of maize in response to individual and combined water and nitrogen stresses. BMC Genomics 14:3. doi:10.1186/1471-2164-14-3

23. Iqbal A, Dong Q, Wang X, Gui H, Zhang H, Zhang X, Song M (2020) Transcriptome Analysis Reveals Differences in Key Genes and Pathways Regulating Carbon and Nitrogen Metabolism in Cotton Genotypes under N Starvation and Resupply. Int J Mol Sci 21 (4). doi:10.3390/ijms21041500

24. Jiang M, Zhang JJP, Physiology C (2001) Effect of Abscisic Acid on Active Oxygen Species, Antioxidative Defence System and Oxidative Damage in Leaves of Maize Seedlings. (11):1265

25. Kanehisa M, Goto S, Kawashima S, Okuno Y, Hattori M (2004) The KEGG resource for deciphering the genome. Nucleic Acids Res 32 (Database issue):D277-280. doi:10.1093/nar/gkh063

26. Kim SG, Wang Y, Wu J, Kang KY, Kim ST (2011) Physiological and proteomic analysis of young rice leaves grown under nitrogen-starvation conditions. Plant Biotechnol Rep 5 (4):309-315

27. Krivosheeva A, Tao DL, Ottander C, Wingsle G, Öquist DGJP (1996) Cold acclimation and photoinhibition of photosynthesis in Scots pine.

28. Krouk G, Lacombe B, Bielach A, Perrine-Walker F, Malinska K, Mounier E, Hoyerova K, Tillard P, Leon S, Ljung K, Zazimalova E, Benkova E, Nacry P, Gojon A (2010) Nitrate-regulated auxin transport by NRT1.1 defines a mechanism for nutrient sensing in plants. Developmental cell 18 (6):927-937. doi:10.1016/j.devcel.2010.05.008

29. Kumagai, E., Araki, T., Ueno, -PRAHA- OJP (2009) Effect of nitrogen-deficiency on midday photoinhibition in flag leaves of different rice (Oryza sativa L.) cultivars.

30. Lauritano C, De Luca D, Amoroso M, Benfatto S, Maestri S, Racioppi C, Esposito F, lanora A (2019) New molecular insights on the response of the green alga Tetraselmis suecica to nitrogen starvation. Sci Rep-Uk 9

31. Laxa M, Liebthal M, Telman W, Chibani K, Dietz KJ (2019) The Role of the Plant Antioxidant System in Drought Tolerance. Antioxidants (Basel) 8 (4). doi:10.3390/antiox8040094

32. Li L, Wang Y, Shen W (2012) Roles of hydrogen sulfide and nitric oxide in the alleviation of cadmiuminduced oxidative damage in alfalfa seedling roots. Biometals : an international journal on the role of metal ions in biology, biochemistry, and medicine 25 (3):617-631. doi:10.1007/s10534-012-9551-9

33. Liu XQ, Liu ZQ, Yu CY, Dong JG, Hu SW, Xu AX (2017) TGMS in Rapeseed (Brassica napus) Resulted in Aberrant Transcriptional Regulation, Asynchronous Microsporocyte Meiosis, Defective Tapetum, and Fused Sexine. Front Plant Sci 8

34. Luo J, Li H, Liu T, Polle A, Peng C, Luo Z-B (2013) Nitrogen metabolism of two contrasting poplar species during acclimation to limiting nitrogen availability. Journal of Experimental Botany 64 
(14):4207-4224. doi:10.1093/jxb/ert234

35. Madhava Rao KV, Sresty TV (2000) Antioxidative parameters in the seedlings of pigeonpea (Cajanus cajan (L.) Millspaugh) in response to Zn and Ni stresses. Plant Sci 157 (1):113-128. doi:10.1016/s0168-9452(00)00273-9

36. Marioni JC, Mason CE, Mane SM, Stephens M, Gilad Y (2008) RNA-seq: an assessment of technical reproducibility and comparison with gene expression arrays. Genome Res 18 (9):1509-1517. doi:10.1101/gr.079558.108

37. Nagalakshmi N, Prasad MN (2001) Responses of glutathione cycle enzymes and glutathione metabolism to copper stress in Scenedesmus bijugatus. Plant Sci 160 (2):291-299. doi:10.1016/s0168-9452(00)00392-7

38. Nasholm T, Kielland K, Ganeteg U (2009) Uptake of organic nitrogen by plants. New Phytol 182 (1):31-48. doi:10.1111/j.1469-8137.2008.02751.x

39. Nawaz MA, Chen C, Shireen F, Zheng Z, Sohail H, Afzal M, Ali MA, Bie Z, Huang Y (2018) Genomewide expression profiling of leaves and roots of watermelon in response to low nitrogen. BMC Genomics 19 (1):456. doi:10.1186/s12864-018-4856-x

40. Nawaz MA, Wang L, Jiao Y, Chen C, Zhao L, Mei M, Yu Y, Bie Z, Huang Y (2017) Pumpkin rootstock improves nitrogen use efficiency of watermelon scion by enhancing nutrient uptake, cytokinin content, and expression of nitrate reductase genes. Plant Growth Regulation 82 (2):233-246. doi:10.1007/s10725-017-0254-7

41. Pagaling E, Yang K, Yan T (2014) Pyrosequencing reveals correlations between extremely acidophilic bacterial communities with hydrogen sulphide concentrations, $\mathrm{pH}$ and inert polymer coatings at concrete sewer crown surfaces. Journal of applied microbiology 117 (1):50-64. doi:10.1111/jam.12491

42. Parisa S (2012) Relationship between drought stress and some antioxidant enzymes with cell membrane and chlorophyll stability in wheat lines. African Journal of Microbiology Research 6 (3). doi:10.5897/ajmr11.1167

43. Patterson K, Cakmak T, Cooper A, Lager I, Rasmusson AG, Escobar MA (2010) Distinct signalling pathways and transcriptome response signatures differentiate ammonium- and nitrate-supplied plants. Plant Cell Environ 33 (9):1486-1501. doi:10.1111/j.1365-3040.2010.02158.x

44. Picault N, Palmieri L, Pisano I, Hodges M, Palmieri F (2002) Identification of a novel transporter for dicarboxylates and tricarboxylates in plant mitochondria - Bacterial expression, reconstitution, functional characterization, and tissue distribution. J Biol Chem 277 (27):24204-24211

45. Quan X, Zeng J, Ye L, Chen G, Han Z, Shah JM, Zhang G (2016) Transcriptome profiling analysis for two Tibetan wild barley genotypes in responses to low nitrogen. BMC Plant Biol 16:30.

doi:10.1186/s12870-016-0721-8

46. Rajendran G, Sing F, Desai AJ, Archana G (2008) Enhanced growth and nodulation of pigeon pea by co-inoculation of Bacillus strains with Rhizobium spp. Bioresource Technol 99 (11):4544-4550 
47. Ravazzolo L, Trevisan S, Forestan C, Varotto S, Sut S, Dall'Acqua S, Malagoli M, Quaggiotti S (2020) Nitrate and Ammonium Affect the Overall Maize Response to Nitrogen Availability by Triggering Specific and Common Transcriptional Signatures in Roots. Int J Mol Sci 21 (2)

48. Richard-Molard C, Krapp A, Brun F, Ney B, Daniel-Vedele F, Chaillou S (2008) Plant response to nitrate starvation is determined by $\mathrm{N}$ storage capacity matched by nitrate uptake capacity in two Arabidopsis genotypes. J Exp Bot 59 (4):779-791. doi:10.1093/jxb/erm363

49. Scheible WR, Morcuende R, Czechowski T, Fritz C, Osuna D, Palacios-Rojas N, Schindelasch D, Thimm O, Udvardi MK, Stitt M (2004) Genome-wide reprogramming of primary and secondary metabolism, protein synthesis, cellular growth processes, and the regulatory infrastructure of Arabidopsis in response to nitrogen. Plant Physiol 136 (1):2483-2499. doi:10.1104/pp.104.047019

50. Shin SY, Jeong JS, Lim JY, Kim T, Park JH, Kim JK, Shin C (2018) Transcriptomic analyses of rice (Oryza sativa) genes and non-coding RNAs under nitrogen starvation using multiple omics technologies. Bmc Genomics 19

51. Siddiqi MY, Malhotra B, Min X, Glass ADMJJoPN, Bodenkunde SSZfPu (2002) Effects of ammonium and inorganic carbon enrichment on growth and yield of a hydroponic tomato crop. 165 (2):191-197

52. Takei K, Sakakibara H, Taniguchi M, Sugiyama T (2001) Nitrogen-dependent accumulation of cytokinins in root and the translocation to leaf: implication of cytokinin species that induces gene expression of maize response regulator. Plant Cell Physiol 42 (1):85-93. doi:10.1093/pcp/pce009

53. Tischner R (2001) Nitrate uptake and reduction in higher and lower plants. Plant, Cell \& Environment 23 (10):1005-1024. doi:10.1046/j.1365-3040.2000.00595.x

54. Wang J, Song K, Sun L, Qin Q, Sun Y, Pan J, Xue Y (2019) Morphological and Transcriptome Analysis of Wheat Seedlings Response to Low Nitrogen Stress. Plants (Basel) 8 (4). doi: $10.3390 /$ plants 8040098

55. Wang WJ, Smith CJ, Chen D (2003) Insight into the Active Organic Nitrogen Pool Estimated by Isotopic Equilibrium Approaches. 67 (6):1773-1780. doi:10.2136/sssaj2003.1773

56. Wang Y, Qu J, Liu H (2007) Effect of liquid property on adsorption and catalytic reduction of nitrate over hydrotalcite-supported Pd-Cu catalyst. Journal of Molecular Catalysis A: Chemical 272 (1):3137. doi:https://doi.org/10.1016/j.molcata.2007.02.028

57. Wang YH, Garvin DF, Kochian LV (2001) Nitrate-induced genes in tomato roots. Array analysis reveals novel genes that may play a role in nitrogen nutrition. Plant Physiol 127 (1):345-359. doi:10.1104/pp.127.1.345

58. Xin M, Wang L, Liu Y, Feng Z, Zhou X, Qin Z (2017) Transcriptome profiling of cucumber genome expression in response to long-term low nitrogen stress. Acta Physiologiae Plantarum 39 (6):130. doi:10.1007/s11738-017-2429-2

59. Xin W, Zhang L, Zhang W, Gao J, Yi J, Zhen X, Li Z, Zhao Y, Peng C, Zhao C (2019) An Integrated Analysis of the Rice Transcriptome and Metabolome Reveals Differential Regulation of Carbon and Nitrogen Metabolism in Response to Nitrogen Availability. Int J Mol Sci 20 (9). doi:10.3390/ijms20092349 
60. Xu G, Fan X, Miller AJ (2012) Plant Nitrogen Assimilation and Use Efficiency. 63 (1):153-182. doi:10.1146/annurev-arplant-042811-105532

61. Yang HC, Kan CC, Hung TH, Hsieh PH, Wang SY, Hsieh WY, Hsieh MH (2017) Identification of early ammonium nitrate-responsive genes in rice roots. Sci Rep-Uk 7

62. Yang SY, Hao DL, Song ZZ, Yang GZ, Wang L, Su YH (2015a) RNA-Seq analysis of differentially expressed genes in rice under varied nitrogen supplies. Gene 555 (2):305-317. doi:10.1016/j.gene.2014.11.021

63. Yang W, Yoon J, Choi H, Fan Y, Chen R, An G (2015b) Transcriptome analysis of nitrogen-starvationresponsive genes in rice. BMC Plant Biol 15:31. doi:10.1186/s12870-015-0425-5

64. York LM, Galindo-Castaneda T, Schussler JR, Lynch JP (2015) Evolution of US maize (Zea mays L.) root architectural and anatomical phenes over the past 100 years corresponds to increased tolerance of nitrogen stress. J Exp Bot 66 (8):2347-2358. doi:10.1093/jxb/erv074

65. Yoshiyuki N, Kozi AJP, Physiology C (1981) Hydrogen Peroxide is Scavenged by Ascorbate-specific Peroxidase in Spinach Chloroplasts. 22 (5):867-880

66. Zhan A, Lynch JP (2015) Reduced frequency of lateral root branching improves $\mathrm{N}$ capture from low-N soils in maize. J Exp Bot 66 (7):2055-2065. doi:10.1093/jxb/erv007

67. Zhao W, Yang X, Yu H, Jiang W, Sun N, Liu X, Liu X, Zhang X, Wang Y, Gu X (2015) RNA-Seq-based transcriptome profiling of early nitrogen deficiency response in cucumber seedlings provides new insight into the putative nitrogen regulatory network. Plant Cell Physiol 56 (3):455-467. doi:10.1093/pcp/pcu172

68. Zhi LI, Shi HZ, Liu GS, Wang DZ, Chao-Long ZU, Yang YFJS (2010) Changes of Carbon-Nitrogen Metabolism of Flue-Cured Tobacco with Sweet Aroma in South Anhui Under Different Fertilization Rates.

\section{Tables}

Due to technical limitations, table 1 is only available as a download in the Supplemental Files section.

\section{Figures}


Fig.1

a

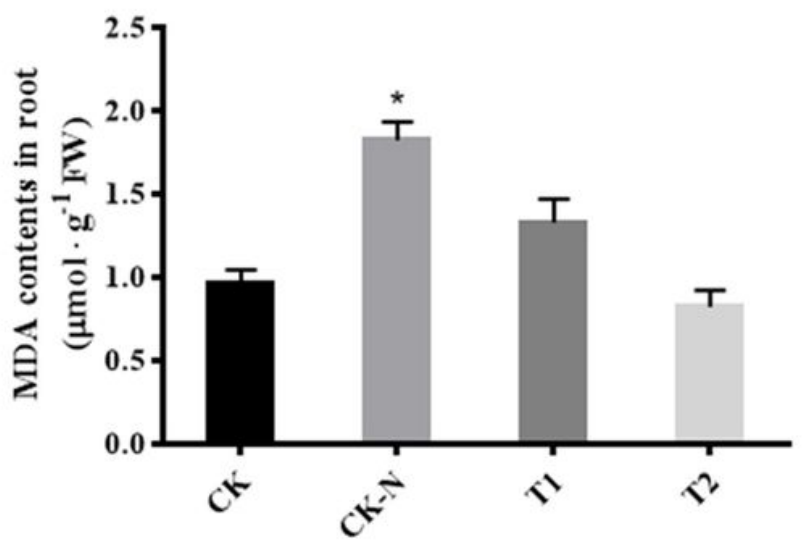

$\mathrm{b}$
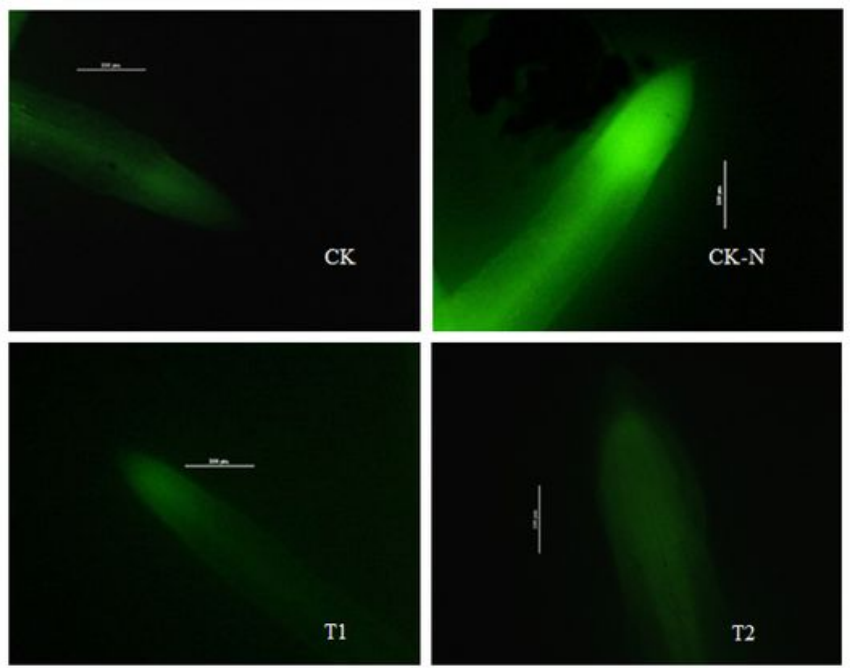

\section{Figure 1}

Effect of $\mathrm{N}$ starvation and re-supply on the lipid peroxidation (a) and ROS accumulation. All the results represent mean \pm standard deviation (SD) of three biological replicates. Data were analyzed with Student's t-test compared with control under similar conditions and indicated by *, $\mathrm{P}<0.1 ; * *, P<0.05$.

Fig. 2

a

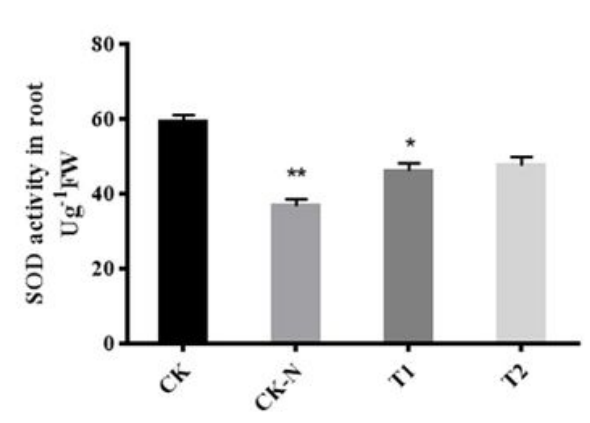

d

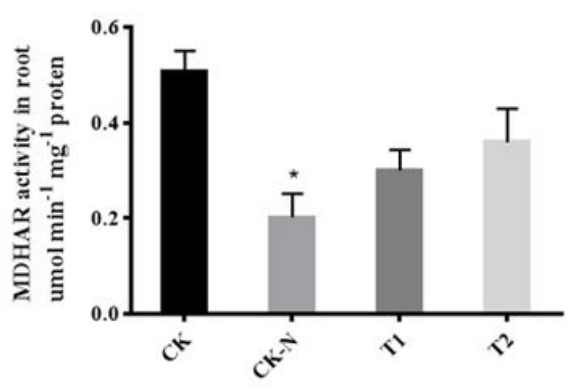

b

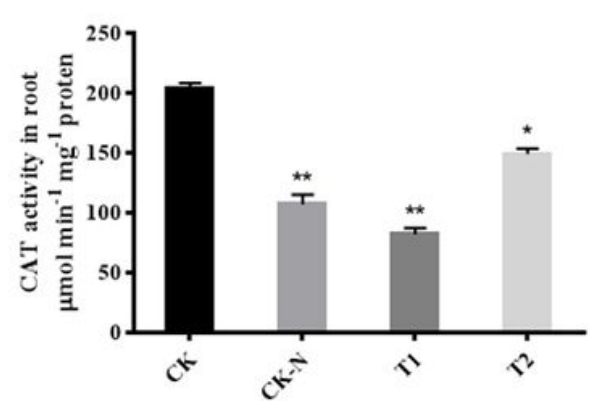

e

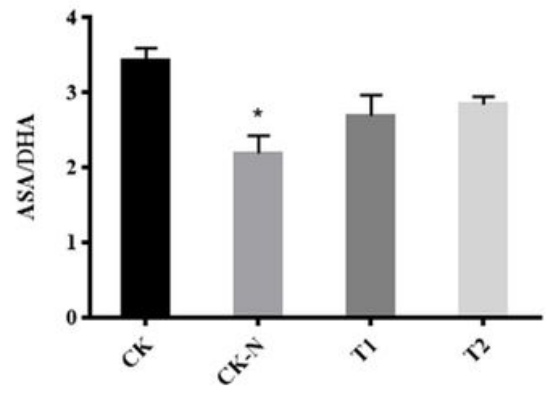

$\mathrm{c}$

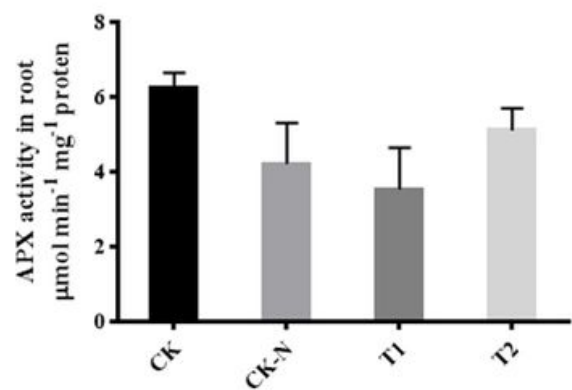

f

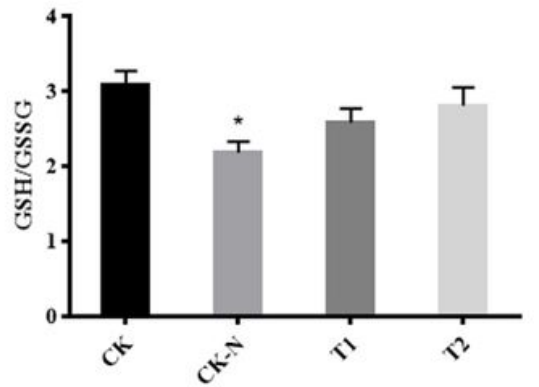

Figure 2 
Effect of $\mathrm{N}$ starvation and re-supply on the activities of SOD (a), CAT (b), APX (c), MDHAR (d) and the ratio of AsA/DHA (e) and GSH/GSSG (f) in the roots of tomato seedling. All the results represent mean \pm standard deviation (SD) of three biological replicates. Data were analyzed with Student's t-test compared with control under similar conditions and indicated by *, $\mathrm{P}<0.1 ; * *, \mathrm{P}<0.05$.

Fig.3

a

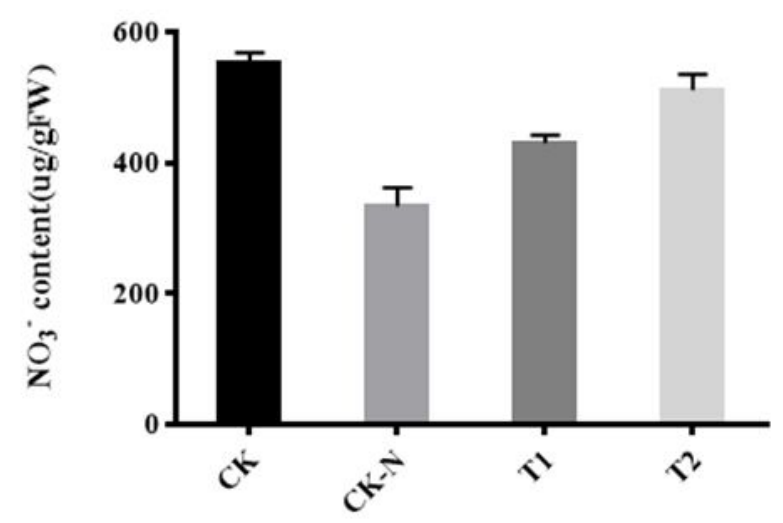

b

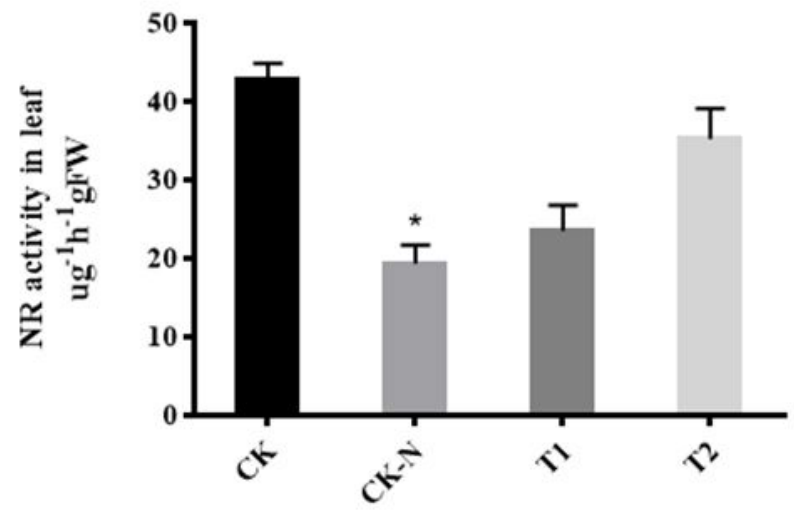

\section{Figure 3}

Effect of $\mathrm{N}$ starvation and re-supply on the nitrate content (a) and nitrate reductase activities (b) in the roots of tomato seedling. All the results represent mean \pm standard deviation (SD) of three biological replicates. Data were analyzed with Student's t-test compared with control under similar conditions and indicated by *, $\mathrm{P}<0.1$; **, $\mathrm{P}<0.05$.

Fig. 4

a

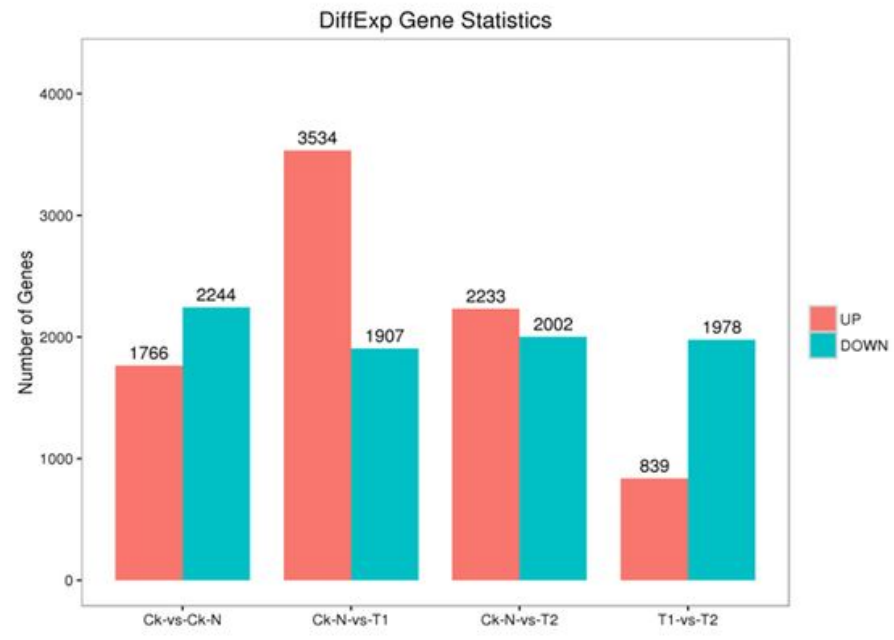

b

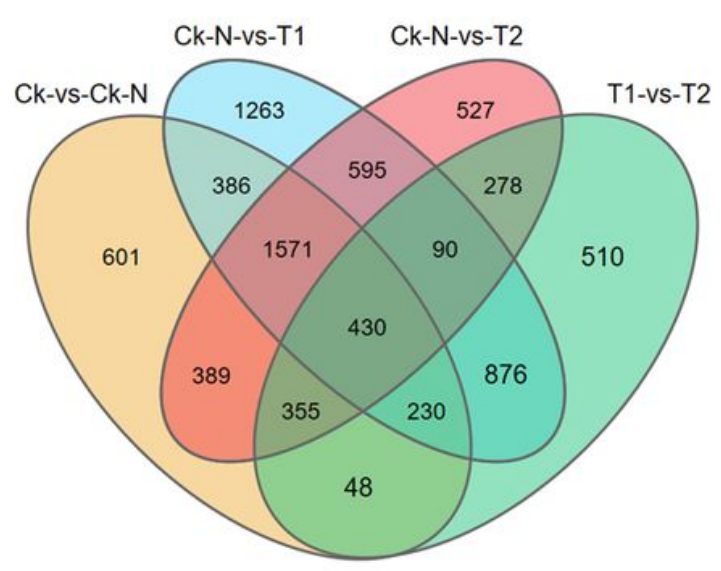


Analysis of significant differences between samples and Venn map of DEGs among different combinations of comparisons.

Fig. 5

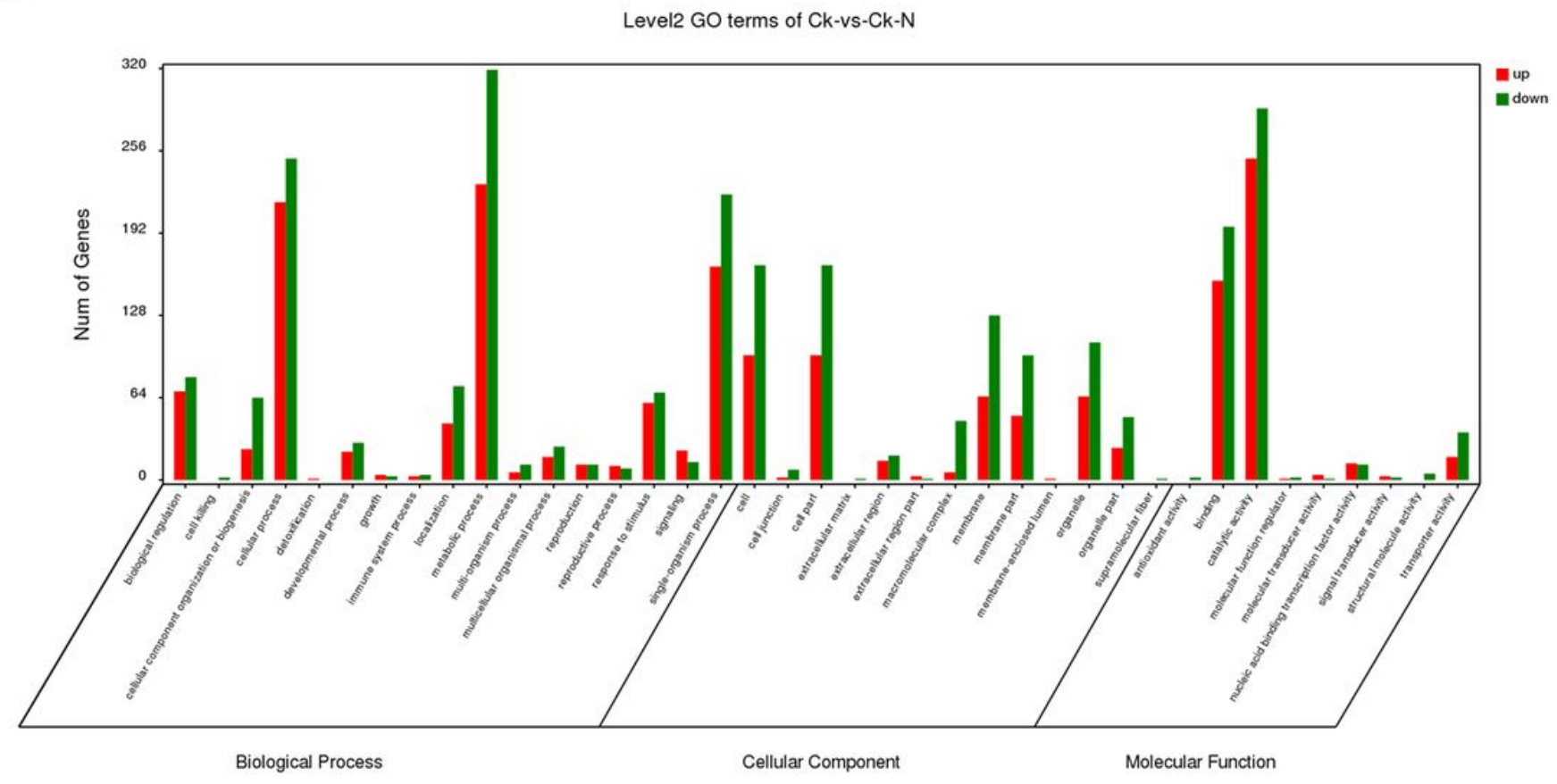

Figure 5

Functional annotation of assembled sequences based on gene ontology (GO) categorization. The unigenes are summarized into three main categories: biological process molecular function and cellular components. 
Fig.6

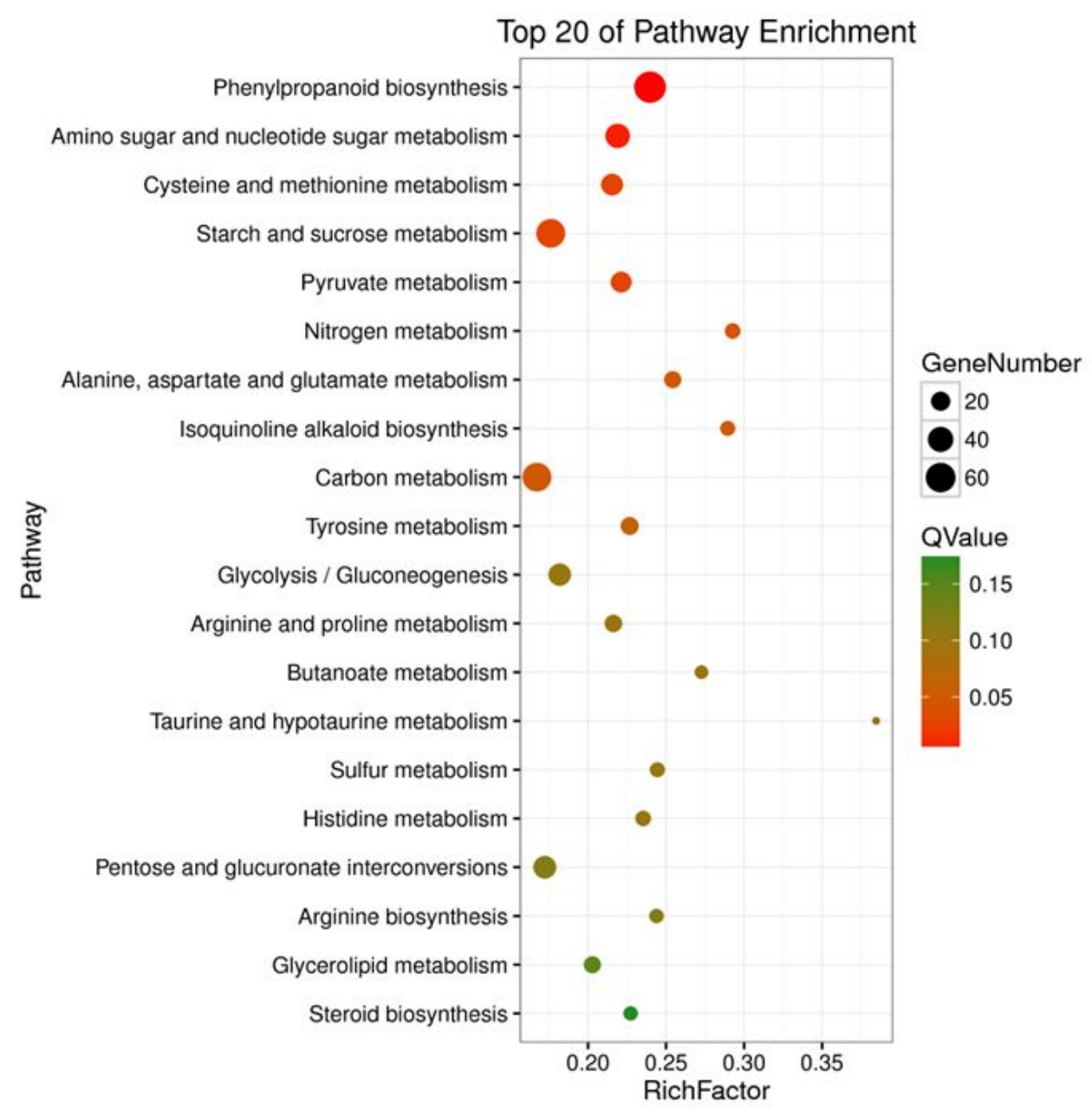

\section{CK VS CK-N}

\section{Figure 6}

The KEGG metabolism pathway categories of DEGs of CK and CK-N. The pathway names are provided in the vertical axis, rich factor in the horizontal axis, size of the point represents the number of DEGs, and the color of the dot represents the q value. 
Fig.7
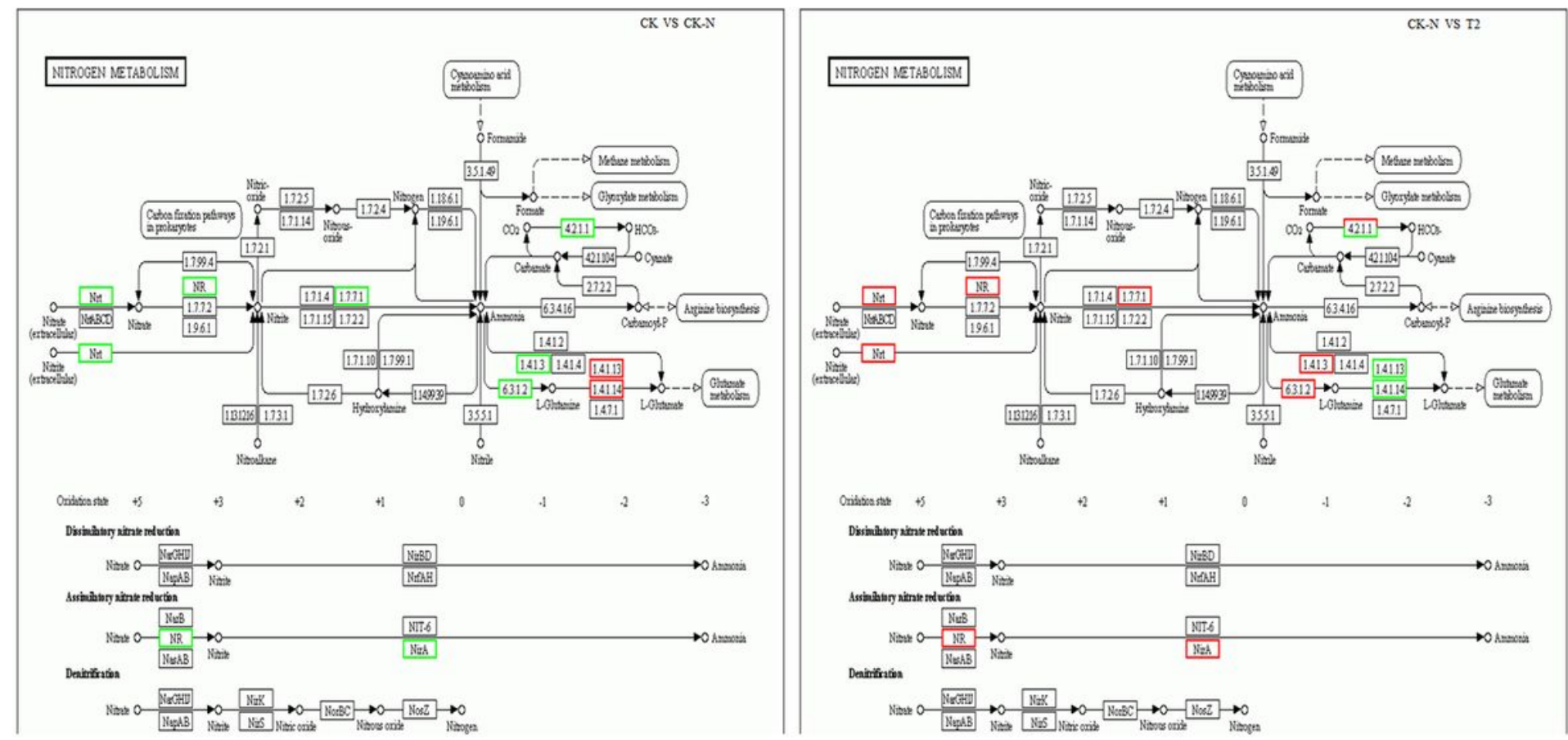

Figure 7

Differentially expressed genes involved in nitrogen metabolism pathway of CK VS CK-N and CK-N VS T2. Green represents genes down-regulated, and red represents genes up-regulated.

Fig. 8

a

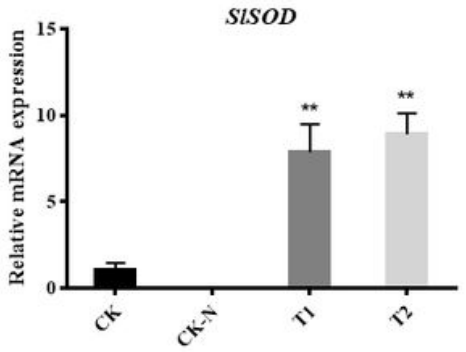

$\mathrm{d}$

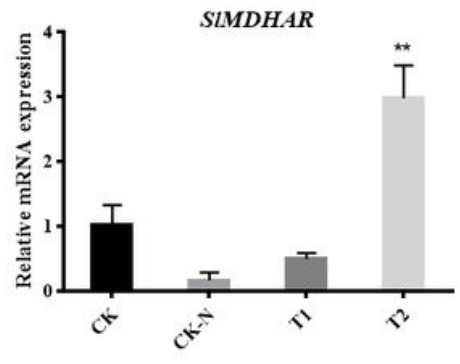

g

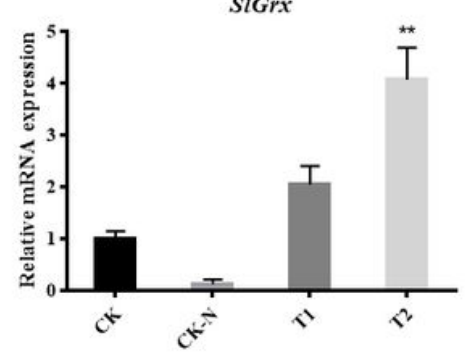

b

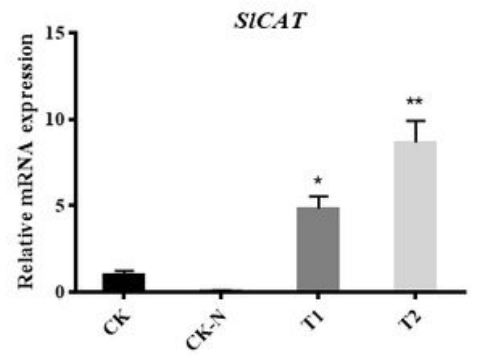

e

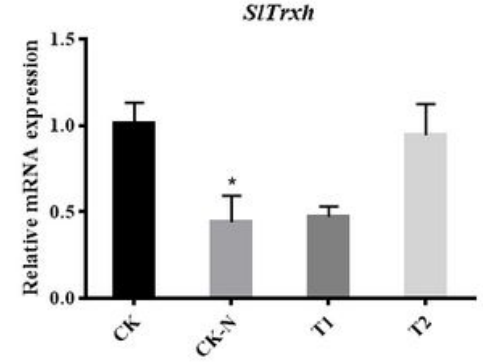

c

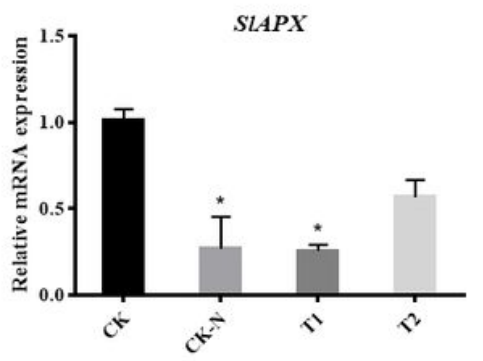

f

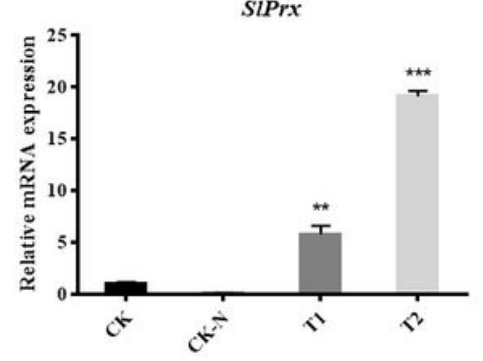




\section{Figure 8}

Quantitative real-time PCR validation of SISOD (a), SICAT (b), SIAPX (c), SIMDHAR (d) SITrx (e), SIPrx (f), SIGrx (g) in tomato seedling roots under $\mathrm{N}$ starvation and $\mathrm{N}$ re-supply treatments. All the results represent mean \pm standard deviation (SD) of three biological replicates. Data were analyzed with Student's t-test compared with control under similar conditions and indicated by *, $\mathrm{P}<0.1 ; * *, \mathrm{P}<0.05$.

Fig.9

a

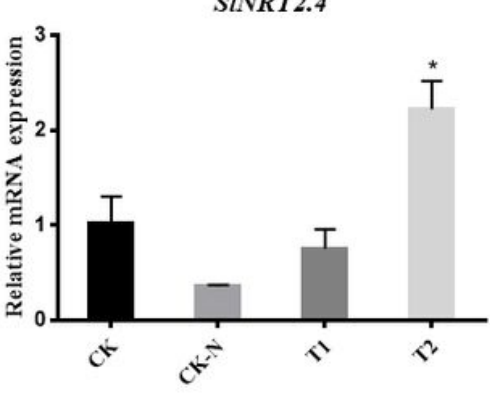

d

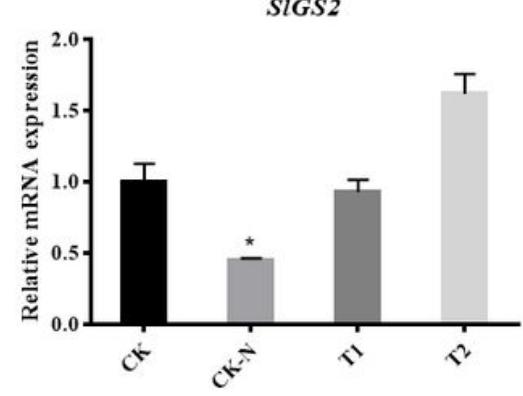

b
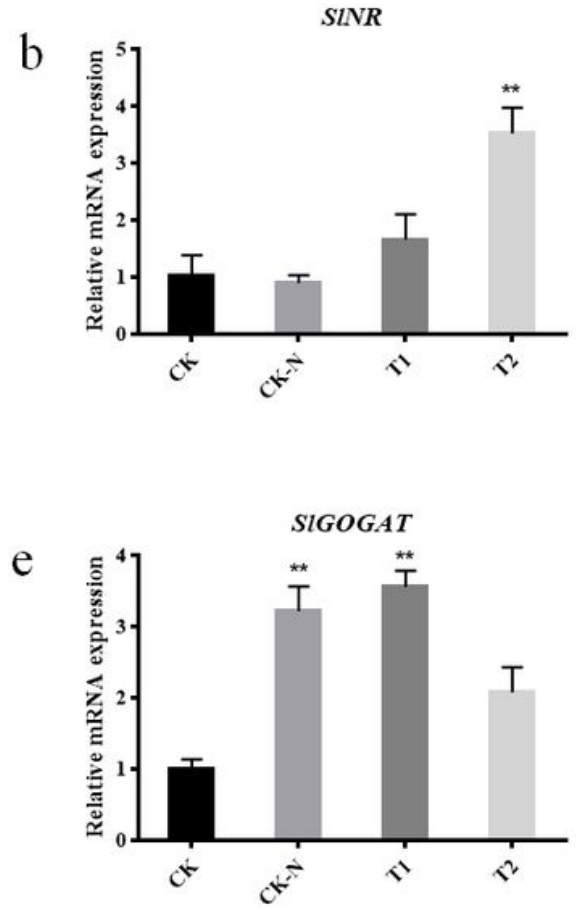

SINiR

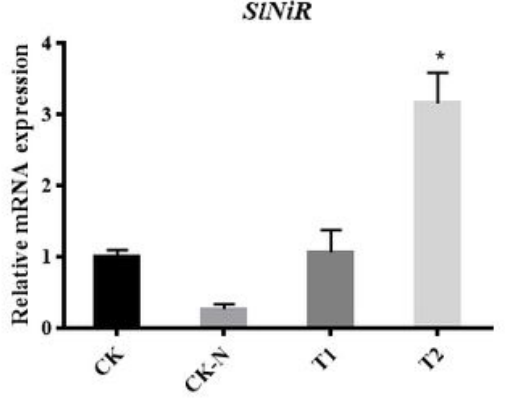

Figure 9

Quantitative real-time PCR analysis of the nitrogen metabolism expression of SINRT2.4 (a), SINR (b), SIGS (c), SINiR (d) SIGOGAT (e) in tomato roots in response to $\mathrm{N}$ starvation and $\mathrm{N}$ re-supply. All the results represent mean \pm standard deviation (SD) of three biological replicates. Data were analyzed with Student's t-test compared with control under similar conditions and indicated by *, $\mathrm{P}<0.1$; **, $\mathrm{P}<0.05$.

\section{Supplementary Files}

This is a list of supplementary files associated with this preprint. Click to download.

- Table1.jpg

- supplementalmaterial.docx 